\title{
On the Effective Approaches to Promote the Brand Construction of Local Enterprises in Suzhou
}

\author{
Yanxin $\mathrm{Gu}^{1, \mathrm{a}}$ \\ ${ }^{1}$ Department of Basic Courses, Suzhou Vocational University, Suzhou, Jiangsu Province, P. R. \\ China \\ agyx88@126.com
}

Keywords: promotion, brand construction, approaches.

\begin{abstract}
Large numbers of brands are owned by Suzhou local enterprises. The number ranks high in our country while the brand value is not. And the brand competitiveness is not strong enough, which has influenced the economic strength and rapid development of the enterprises. Therefore, Suzhou local enterprises need further development. For instance, they could take full advantage of Suzhou's rich cultural heritage and accelerate the construction of strong brands. In order to enhance the brand value and its competitiveness, the enterprises must develop the right brand development strategies, strengthen the scientific management of their brands, and attach great importance to their brand culture.
\end{abstract}

\section{Introduction}

With the formation of economic globalization and world market, the competition between enterprises has changed from relying solely on the product quality, price and service into the competition between the technique and the brand. Strong brands with proprietary intellectual property rights have become the company's most valuable assets. Suzhou was once famous for outward-looking economy. Under the impact of the international financial crisis, it timely adjusts the strategic deployment and accelerates the transformation of the mode of economic development. Meanwhile it also promotes the transformation and upgrading of the economic structure, enhances the capability of independent innovation, and finally a number of local enterprises with famous brands appear. Although a number of local enterprises with brand impact such as Bosideng, Menglan and Positec have sprung up in Suzhou, but there is a lack of famous brands that enjoy a good reputation at home and abroad, and most brands have low brand value and weak brand competitiveness. Therefore, establishing strong brands becomes the strategic choice of the development and growth of local enterprises in Suzhou.

\section{Correctly Formulate the Brand Development Strategy}

To find market gaps with their characteristics. The brand "solidifies continued innovation, scientific management, excellent quality, remarkable service and enterprise culture of the enterprise for many years which is a powerful weapon for the enterprise to obtain market resource allocation priority." [1]5 Brand building is a complex systematic process whose success or failure can be directly affected by the selection of brand development strategies. To build a strong brand, a long-term credit accumulation of technology, product, quality, service, and authentication by consumers is needed. Money can not buy famous brand, and it is also not easy to merge by a joint venture. Enterprises should formulate correct strategies according to their own characteristics. Small and medium-sized enterprises can make full use of the advantages of location, quick market reaction and featured products to choose the target industry of narrow field, or the market segments that have not been taken into account by large enterprises, and they can take gap-oriented strategy to establish the brand. When Longliqi Group in Changshu marched to the daily chemical industry, they found that rural consumers could not afford to buy high-priced brand, so they decisively abandoned the widely adopted high profit strategy, and attracted the rural consumers by ultra low prices. "One-dollar snake 
ointment" gains favor of the majority of rural consumers and enjoys an extremely high visibility and reputation in the countryside. It's a success of the strategy of "surrounding the cities with the countryside". ${ }^{[2] 33}$

To build a world famous brand by OEM. In the tide of economic globalization, it's a strategic option for Chinese industry and enterprise to take the "going out" strategy to actively participate in international competition and to seek more space for development. How to "go out"? Is it the capital or the brand that "goes out"? Some enterprises with foresight choose the latter, such as Bosideng and Positec. The two companies gathered capital, techniques and management experience in the process of OEM, and created brands when conditions permitted. Positec was the first OEM of domestic electric industry that served for international brands such as Black \& Decker, BOSCH and Electrolux. Years of working experience in foreign trade enterprises trained the enterprise an international vision. Positec felt a strong sense that to create independent brands is the way of significant development. The enterprise made a second innovation on the basis of the introduction, digestion and absorption to create an independent brand WORX, breaking the situation that the international market of electric tool was monopolized by foreign companies.

To attach importance to creative design and abandon imitation. In the information era, the recognizable differences between products become smaller and smaller. It appears that product innovation and marketing and brand image become increasingly important, which all rely on creative design to achieve. Therefore, creative design is the inevitable requirement of the survival and development of the products and also the first impetus for industries to transform and upgrade. If the enterprise wants to change from the competition for cost into competition for value, and build up the advantages of efficiency and cost performance, they must improve the level of creative design and forge ahead towards high-end products with high design content and strong fashion creativity. Among the reasons why Bosideng can become a leading brand of the industry, the most valuable experience is that they attach great importance to creative design. Bosideng broke through the traditional concept of down coat, and creatively launched "autumn down coat", a new concept of fashion down jacket which is light and fashionable and has technology texture. Bosideng men's wear advocates the philosophy of "quality living", and guides the modern men's consumer groups to dressing in different styles in different occasions.

\section{Continuously strengthen scientific brand management}

Effectively establish brand orientation. Brand orientation means that the enterprise in the market for specific consumer groups shape its own brand image which is different from the competitors so that the enterprise's products and services "are able to occupy a unique position in the minds of consumers in the target market" ${ }^{\text {[3]300 }}$. If the brand orientation is not clear, it will confuse the audience's awareness and the competitiveness of the brand will be weakened. Goodbaby Group has three brands of different levels, namely, "Goodbaby EU", "Goodbaby" and "Happydino". The brand orientation of "Goodbaby EU" which is regarded as the company's high-end brand is that "dare to be the first". Its products are simple and fashionable which fully embody the characteristics of high grade. "Goodbaby" is the company's flagship brand, positioning on that "creativity links the world". "Creativity" means innovation, and the first baby carriage of Goodbaby with four functions is exactly a product of this kind of independent innovation. The word "world" means that the pushchair of Goodbaby not only is the domestic market leader, but also moves towards the world. "Happydino" positions on "providing value to you" whose products have high price ratio to meet the needs to save money of the low-end market users. Three brands have clear brand orientation aiming at different segments of the consumer. The case of "Goodbaby" proves that the market segment and correct positioning will shape a clear target consumer and form a stable consumer groups.

Focus on building brand personality. Brand personality refers to a kind of psychological characteristics that is given through brand communication and contains the emotional added value and life value namely "the traditional features of human nature such as warmth, care and sentiment" $\left.^{\text {"[ }}\right] 110$ of its relations benefit person. The brand that has unique personalities is able to seize the consumer interests, and strongly attract the consumers who agree with this value, and make them 
have a good impression and loyalty to it. "The most durable sense of a brand should be the value, culture and personality." [5]416 "Snow Flying" is a rising star of China's down clothing industry aiming to be dynamic and vibrant whose jumping color, passionate personality and stylish design enjoy great popularity among the young. Therefore, each brand must fully tap the consumer's interest in a certain point, and highlight its core value and once the consumers have the demand in this area, it will first occur to them. This is what we say "you will change for the brand if it touches your mind, but you will be dedicated to it if it touches your heart". [6]105

Strive to master the core technology. Weak independent innovative ability and the missing core technology are the vital reasons for the feeble brand value and low competitive ability. Throughout the international famous brands, there is always a strong support from the core technology based on proprietary intellectual property rights behind the unique products and services. Thus, to build famous brands, enterprises must enhance the capability of independent innovation, combine it with brand building, and actively make original and integrated innovations and then introduction, absorption and re-innovation. ${ }^{[7] 80}$ Positec started from four employees and one apartment, and then developed into a professional international conglomerate which possesses 13 oversea marketing subsidiaries, three R \& D centers and high-end private brands. The success of Positec provides precious experience to the local enterprises that you must master your own core technology to create a brand. By virtue of the world's most advanced electric tool design concept, Positec developed a number of electric tools that are innovative in function, comfort to use and original in design. Positec has focused on protecting intellectual property rights all along. As of September in 2013, the total number of patent applications of the company is 2466, of which more than 1094 pieces are inventions ranking the forefront among the industry in the world. Positec is supported by intellectual property rights, and changes from the pattern of "made in China" into "created in China" by independent R \& D brand products.

\section{Attach great importance to the construction of brand culture}

The brand culture is the sum of ideologies such as values in brand, aesthetic taste, personality cultivation, fashion taste and emotional appeals and so on. "The brand with good cultural heritage can bring people enjoyment of spirit and comfort of soul." ${ }^{[8] 16}$ Consumers choose a brand not only for the product quality, function and after-sales service, but in hope to experience a realization of the self value brought by the brand, a reaction of cultural value and a release of personal feelings. ${ }^{[9] 11}$ With the improvement of the degree of homogeneity of goods, the enterprises have difficulties in making differences in aspects like price and service. To gain market competitiveness, highlighting the brand culture is a good strategy.

The humanistic spirit should be adhered to in the construction of brand culture. Humanistic spirit is a kind of cultural ecology where the idea of people first, symbiotic culture and social responsibility are the embodiment. Brand culture construction should adhere to the leadership of socialist core values, and the ideological concept, value orientation, moral sentiment and aesthetic taste reflected by brand culture must be consistent with the excellent culture of Chinese nation. In the brand culture construction, the enterprises "should carefully and reasonably promote healthy consumption view, aesthetic view and moral view." They also should stimulate an affirmative mental outlook so as to serve for civilized and harmonious cultural ecology. ${ }^{[10] 98}$ 。

Pour into the traditional culture of Suzhou in the construction of brand culture. Integrating excellent national traditional culture into the brand culture is more likely to enable consumers to resonate, and to make the brand a more lasting vitality and market competitiveness. ${ }^{[11] 153}$ The traditional culture of Suzhou has rich humanistic connotations, namely the excellent tradition of esteem education, qualities of treasuring harmony, absorption and open-minds, characteristics of delicacy, soft, gentleness and grace, and the ubiquitous humanistic thoughts and spirits, all of which have important enlightenment reference function and practical guiding significance for the brand culture construction of enterprises in Suzhou. When growing excellent brands, the local enterprises of 
"Suzhou culture" can make full use of the precious resources, pour into the elements of Wu culture and advance the brand connotation.

Taihu Snow Silk absorbs the elements of delicacy and elegance of Suzhou traditional culture in the brand culture construction. The brand concept that "Taihu Snow Silk, see the true love" comes from the snow on the shore of Lake Taihu that pursues to be "green, comfortable, healthy and fashionable". Snow of Lake Taihu from the heaven melts environmental protection concept into the brand soul through green products. Home textiles of Taihu Snow Silk are simple but elegant, and are poured into classic design and rigorous process which not only integrate into the concept of home decoration of modern fashion and low carbon, but also manifest the distinguished character of silk products. When purchasing and using the products, consumers fully experience the brand culture that "to be concise is not to be simple; concision discloses delicacy and wateriness shows the beauty of luxury".

Menglan captures the harmonious quality and people-oriented feelings of Suzhou's traditional culture in the construction of brand culture. Adhering to the concept that "perfect quality comes from sincere creation", and the core value of "nature, harmony and integration" so as to "contribute quality and deliver friendship" to consumers. Crew of Menglan knows that, with the improvement of social material, cultural and ideological civilization, home decoration has become a kind of culture and taste. Home textile has also gone to individuation and fashion-orientation. So each time when the crew of Menglan builds a product, they commit themselves to realize the unity of man with nature and environment. They emphasize the harmony of bedding, indoor soft decorations and home environment in order to let consumers feel deeply the harmonious culture of "sweet dream and excellent quality" of Menglan.

Bosideng injects the connotation of pioneering of the traditional culture of Suzhou during building the brand culture. Fed by Suzhou's traditional culture, Bosideng combines classics with tradition, innovation with fashion. Declaration of beauty is full of care and self-confidence and contains inner strength of go-ahead. Beauty is not only showing from the outside, but it comes from the tireless pursuit, rich experiences and accumulation which are exactly the charm of Bosideng. The brand concept of Bosideng has sunk deeper and deeper into people's hearts and become a life idea that inspires people to be confident and calm and to outdo themselves.

Twenty-first century is the era of winning by bran. Relying on patented technology to create a strong brand has become the strategic choice of enterprises. Suzhou has a large number of brand enterprises such as Bosideng, Menglan, Goodbaby, Positec, Taihu Snow, and Kangli. They stand erect for decades in the day of extremely intense competition and become the best ones of the industry, accumulating a lot of valuable experience. Although the number of independent brands of domestic enterprises in Suzhou is the top of the country, but few are well-known brands at home and abroad which impacts the economic strength and rapid development of the enterprises .In order to enhance the brand value and competitiveness, enterprises must establish the correct brand development strategy and strengthen the scientific management of the brand. The city Suzhou is a charming and full of cultural heritage. When building the brand, enterprises can fully excavate the rich resources of traditional culture in Suzhou, pour into the elements of $\mathrm{Wu}$ culture and advance the brand connotation.

\section{References}

[1] DUAN Ruichun. Innovative Enterprises: Intellectual Property and Brand Strategy [J]. CHINA SOFT SCIENCE, 2005, 12.

[2] YU Mingyang \& YANG Fangping. Brand Orientation [M]. Wuhan: Wuhan University Press, 2008.

[3] (US.) Philip Kotler. Translated by WANG Yonggui. Management (14th edition • global edition) [M]. Beijing: China Renmin University Press, 2012.

[4] (US.) David A.Aaker. Translated by LI Zhaofeng. Building Strong Brands [M]. Beijing: China Machine Press, 2014. 
[5] (US.) Philip Kotler. Marketing Management: Analyzing, Developing, Planning and Managing (9th edition) [M]. Shanghai: Shanghai People's Publishing House, 1999.

[7] SUN Guohui \& WANG Shenghui. Thoughts on Quickening the Development of Chinese Enterprises' International Famous Brands [J]. JOURNAL OF CENTRAL SOUTH UNIVERSITY(SOCIAL SCIENCE), 2009, 1.

[8] ZHOU Chaoqi, HOU Longwen \& XING Hongping. Brand Culture: Commodity Culture, Philosophical Idea and Its Performance [M]. Beijing: Economy \& Management Publishing House, 2002.

[9] YU Mingyang \& DAI Shifu. Brand Culture [M]. Wuhan: Wuhan University Press, 2008.

[10] ZHU Jianqiang. Humanistic Meaning and Social Influences of Brands [J]. Journal of Xiamen University (Arts \& Social Science), 1997, 2.

[11] NIU Yuanshuai, YIN Guoqiang \& QIU Shu. Construction of Brand Culture in Domestic Medium-sized and Small Enterprises [J]. MARKET MODERNIZATION, 2008, 10. 